\title{
Application of Fuzzy Logic Temperature Controller for Water Bottle Industry
}

\author{
Egoigwe Sochima Vincent $^{1} \quad$ Nwobi Chukwudumebi $^{1} \quad$ Araoye Timothy Oluwaseun ${ }^{2}$ \\ Okonkwo Emenike George ${ }^{3}$ Rev. Fr. Anoliefo Edward ${ }^{1} \quad$ Chijindu Vincent Chukwudi $^{1}$ \\ 1.Department of Electrical and Electronics Engineering, University of Nigeria, Nsukka, Nigeria \\ 2.Department of Electrical and Electronics Engineering, Enugu State University of Science and Technology, \\ Enugu, Nigeria \\ 3.Department of Metallurgical and materials Engineering, University of Nigeria, Nsukka, Nigeria
}

\begin{abstract}
The mathematical modeling involves convectional controller which affect the performance non-Linear and complex control system of the Bottle water industry. The system instability can be overcome by using intelligent controller to control and Monitor water temperature within a specific period of time in order to avoid overshoot and absolute error, with better temperature tracking capability. However, most industry does not have accurate and reliable monitoring mechanism capable of sensing when the water Temperature increases. The fuzzy Logic is used to control the Temperature of Bottle water at difference time of operation. This operational failure can be overcome by designing a model that will monitor and control the water temperature process thereby improving temperature control in water bottle industry using Fuzzy Logic Controller. MATLAB Software was used to carry out simulations to develop Temperature control in Bottle water industry with aims of improving operational mechanism of the industry. This model can then be trained with result gotten from the mathematical model in order to monitor and control the Water Temperature. The result showed that Bottle water Temperature with and without Fuzzy Logic Controller were $85^{\circ} \mathrm{C}$ and $65^{\circ} \mathrm{C}$ respectively. The Temperature increased by $20^{\circ}$. With these results, it shows that using fuzzy Logic Controller gives a better result than when fuzzy logic is not used.
\end{abstract}

Keywords: Fuzzy Logic, Temperature, Control, MATLAB, Monitor.

DOI: $10.7176 / \mathrm{CEIS} / 10-2-02$

Publication date:March $31^{\text {st }} 2019$

\section{0 introduction}

Temperature regulation is a very important criterion, needed to process various control systems particularly the bottle water temperature regulation [5]. The utilization of non-linear control system is the most essential and widely applied [8] in process control industry and its use in the manufacturing of different products of drink including chocolate drink, milk products, fruit juice etc. Quite a number of industries utilize bottle water temperature control. This control mechanism is very crucial to obtain quality end-products from the production line. Hence, it is important to attain the specified temperature without transgressing the specified duration in order to prevent outsized overshoot [3]. Temperature is a basic quantity that applies to measurement and control. The PI [13] and PID conventional controller [2] are often employed in temperature control system to regulate the temperature in order to obtain the specified temperature level. PID controller forms conventional control algorithm which is employed in process control discipline. The prevalent acceptance of the conventional control in process control has shown operational satisfaction as a result of its imperviousness to failure and overall effectiveness, spanning over a broad range of operating constraints, and somewhat, its simplicity of purpose. The main disadvantage of the conventional controller is that it is prone to alteration of system parameters, delays, non-linearity applied to acquire zero overshoot. Another drawback of conventional controller is that it is challenging to design a mathematical model which will handle unnecessary rigorosity, preciseness and accuracy. The functionality of the controller reduces, particularly for nonlinear and ambiguous control problems, when the mathematical model of the plant is not accurate.

The difficulties described can be mitigated using an alternative technique which utilizes the unconventional control technique. This paperwork employs the artificial intelligence (AI) unconventional control technique to improve the efficiency of the controller for various plants. Artificial intelligence techniques used for effective control of the PID controller parameters include Neural Network (NN) [7], Fuzzy Interference System (FIS)[9], and Adaptive Neuro-Fuzzy Interference System (ANFIS)[6]. Rapid advancement of processing capability of modern digital controllers makes Fuzzy Logic Control (FLC) and Neuro-Fuzzy systems (NFS) feasible and attractive to industries. This paper employs a comparative study based on performance index of conventional controller PID and Artificial Intelligent Controllers (FLC \& ANFIS) considering Absolute Error (AES)[10], overshoot, delay and tracking capability [4].

\section{Fuzzy Logic Technique}

Fuzzy logic is a form of intelligent controller, stemmed from fuzzy set theory to handle reasoning which is rather 
estimated than precise. It was created for operational control of knowledge based systems and classifies data as true or false. Its ease of application has made it a widely used alternative for implementing knowledge based system. Fuzzy logic implements the fuzzy sets and rules to provide system control. In contrast to the conventional set theory where there is a clear cut on the set to which an element belong, fuzzy set theory allows partial affiliation of the element in the set. Fuzzy set is a class with various grades of membership [5], [16], [18]. Fuzzy controllers are often classified under multi-input-multi-output (MIMO) systems because it is capable of processing several variables from the system simultaneously. It is controller similar to a linear or nonlinear state feedback controllers [12]. Objects of treatise are to a large extent allowed to be general and more complex than the object of treatise in the conventional logic system and probability theory [1]

Fuzzy systems have been largely utilized in control systems. It performs control actions (output) using a rule base that computes some inputs (i.e. difference in errors between control variables and references.

There are four major components of a fuzzy system which include fuzzification, fuzzy rule base, fuzzy output engine and defuzzification. Fuzzification entails the conversion of numerical inputs and output variables into linguistic terms (such as low, high, big, small, etc.) and the matching degree of the each membership function is ascertained. Then, developed fuzzy rules are applied to process the output membership values. Lastly, the defuzzification step involves interpreting the linguistic results obtained into real values by applying the rule base given. The defuzzification phase handles the conversion of the fuzzy results from the fuzzy system into discrete values [11], [14], [15].

The block diagram of the fuzzy logic implementation process is shown in Figure 1[10].In addition, the defuzzification method can be expressed mathematically as follows [16]:

$$
\left(y_{i}\right)_{d}=\frac{\sum_{i=1}^{n} \mu\left(y_{i}\right) y_{i}}{\sum_{i=1}^{n} \mu\left(y_{i}\right)}
$$

where; $\left(y_{i}\right)_{d}$ is the defuzzified output, ${ }^{y_{i}}$ is the output value (or the centroidal distance from the origin) in the $i^{\text {th }}$ subset, and $\mu\left(y_{i}\right)$ is the membership value of the output value in the $i^{\text {th }}$ subset.

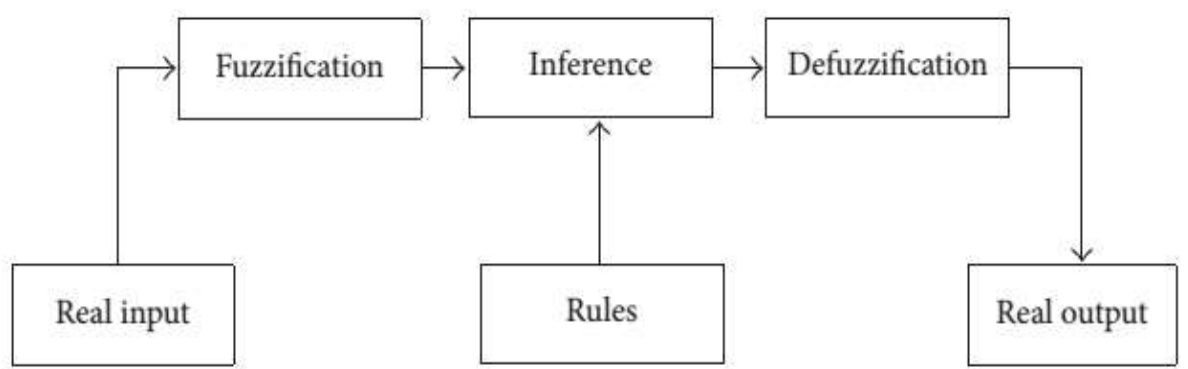

Figure 1: The block diagram of the fuzzy logic implementation process[10]

\section{Materials and Methods}

This paper develops a fuzzy logic temperature controller to control and monitor the bottle water industry in order to stabilize constantly and effectively the water temperature. The control unit was designed to analyzed the temperature of the water bottle industry with the aims of improving productivity and performance of the industry. The controller decides the necessary action for the water valve of liquid into the bottle. The condition of the water temperature of bottle industry is written in Fuzzy Logic Controller Rule Editor using MATLAB/SIMULINK and a Graphic User Interface (GUI) was performed for convenient input of the data.

\section{A. Mathematical Model of Bottle Water.}

Water enters a tank from the top and leaves through an orifice in its base. The rate that water enters is proportional to the voltage, $V$, applied to the pump. The rate that water leaves is proportional to the square root of the height of water in the tank.

A differential equation for the height of liquid in the tank, $H$, is given by:

$$
\frac{d}{d t} V_{e q}=A \frac{d H}{d t}=C V-K \sqrt{H}
$$

where $V_{e q}$ is the volume of liquid in the tank, $A$ is the cross-sectional area of the tank, $C$ is a constant related to the flow rate into the tank, and $K$ is a constant related to the flow rate out of the tank. The equation describes the height of liquid, $H$, as a function of time, due to the difference between flow rates into and out of the tank. The 
equation contains one state, $H$, one input, $V$, and one output, $H$. It is nonlinear due to its dependence on the squareroot of $H$. Linearizing the model, using Simulink Control Design, simplifies the analysis of this model [17]. The level is sensed by a suitable sensor and converted to a signal acceptable to the controller. The controller compares the level signal to the desired set-point temperature and actuates the control element. The control element alters the manipulated variable to change position of the valve so that the quantity of liquid being added can be controlled in the process. The objective of the controller is to regulate the level as close to the set point as possible.

The dynamics of the Bottle water is given by:

$$
\frac{d T}{d t}=\frac{F}{V}\left(T_{i}-T\right)+\frac{Q}{V C_{p} \ell}
$$

Where $\mathrm{T}$ is the can Temperature, $\mathrm{F}$ is the flow rate, $\mathrm{T}_{\mathrm{i}}$ is the inlet temperature, $\mathrm{V}$ is the volume of the can, $\mathrm{Q}$ is the heat input, $C_{p}$ is the specific gravity and $\ell$ is the density of water.

Hence, the electrical model is given by:

$$
\frac{d y}{d t}=\frac{f(t)}{C}+\frac{y_{0}-y(t)}{R C}
$$

Where $\mathrm{t}$ is the time, $\mathrm{y}(\mathrm{t})$ is the output temperature in ${ }^{0} \mathrm{C}, \mathrm{F}(\mathrm{t})$ is the heat flowing inward, $\mathrm{y}_{0}$ is the room temperature. When the $\mathrm{R}$ and $\mathrm{C}$ are constant.

The step response is given by:

$$
y(k+1)=a\left(T_{s}\right) y(k)+b\left(T_{s}\right) u(k)
$$

Where $\mathrm{k}$ is the discrete time-index, $\mathrm{U}(\mathrm{K})$ is the system input, $\mathrm{y}(\mathrm{k})$ is the system output and $\mathrm{T}_{\mathrm{s}}$ is the sampling Period.

$$
\begin{aligned}
& a\left(T_{s}\right)=e^{-\alpha\left(T_{S}\right)} \\
& b\left(T_{s}\right)=\frac{\beta}{\alpha}\left(1-e^{-\alpha\left(T_{S}\right)}\right) \\
& y(k+1)=a\left(T_{s}\right) y(k)+\frac{b\left(T_{s}\right)}{1+e^{(-0.5 y(k-\gamma)}}+\left(1-a\left(T_{s}\right) y_{0}\right.
\end{aligned}
$$

\section{B. Training of Fuzzy Logic Controller}

The paper developed a program in MATLAB/SIMULINK for fuzzy logic controller model and implemented using fuzzy logic toolbox in MATLAB.

The steps involved are:.

i. Design of a membership function that analyses the bottle water industry. This is done by the fuzzification of variables, which involves a transformation of domain; crisp variables into fuzzy inputs. This helps to stabilizing the bottle water temperature. A membership function is a degree which produced input value to the fuzzy controller. For its directness, the linear function is embraced as the membership evaluation function of input/output. In this study the output membership functions are assumed symmetrical and the commonly used continuous centre of gravity (COG) also known as the centre of area (COA) or centroid method are applied to the defuzzification.

ii. Designed of a fuzzy rule that sticks in the bottle water temperature. The output of the fuzzy controller is depends on position of the membership function (MF) and the fuzzy rule base (FRB). The position of the membership function decides the distribution of the set parameters.

To design a fuzzy rule, the following rules are used: In conclusion.

$>$ if (water level is normal) and (valve controller open fast) then (water temperature is very high)

$>$ if (water level is normal) and ( valve controller open closely) then (water temperature is slightly high )

$>$ if (water level is normal) and (valve controller closed closely) then (water temperature is high )

$>$ if (water level is not normal) and (valve controller open fast) then (water temperature is Average)

$>$ if (water level is not normal) and (valve controller open closely) then (water temperature is weak )

$>$ if (water level is not normal) and (valve controller closely closed) then (water temperature is poor)

\section{Discussion of Result}

The simulation results are presented according to bottle water temperature without and with fuzzy logic controller: Figure 1 shows the designed fuzzy logic controller SIMULINK model for controlling and monitoring of water Bottle industry. The result shows the model Simulink which can used to control water Temperature of the industry at difference time.

Fig 2. Shows the Simulink steps response of Bottle water temperature with and without fuzzy controller. The 
result shows the increase in Amplitude of Water as the time increase. The Amplitude increase when fuzzy logic controller is incorporated into the system compare to when is not used.

Fig3. The Bottle Water Temperature without Fuzzy logic controller. The result reveal that as the Water Temperature increase, time also increase. Hence there is linear relationship between the time and the Bottle water tempearture when the volume of water is contant.

Fig4. Comparing the Bottle Water Temperature of industry with and without fuzzy controller. The result shows the Bottle water Temperature with and without fuzzy logic controller. The fuzzy logic controller monitor and control the Temperature of Bottle Water with time difference at contant volume. Its shows that the Temperature of Bottle water when fuzzy logic controller is not used is $65^{\circ} \mathrm{C}$ while the Temperature of Bottle water when fuzzy logic controller is used is $85^{\circ} \mathrm{C}$. With this result it shows that there is an improvement of $20^{\circ} \mathrm{C}$ Temperature of Bottle water when Fuzzy Logic Controller is used.

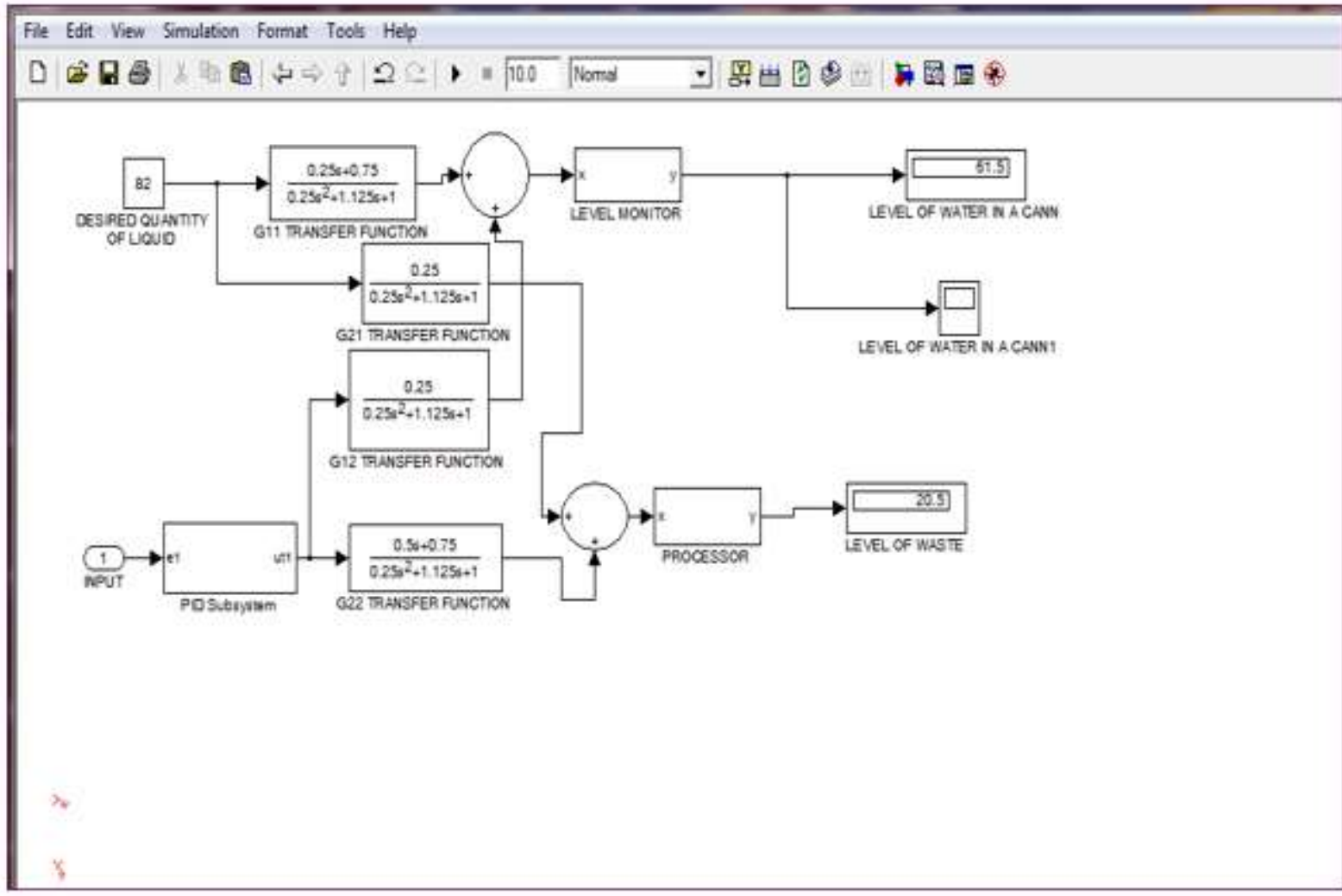

Figure1 shows the designed fuzzy logic controller SIMULINK model for controlling and monitoring of water Bottle industry 


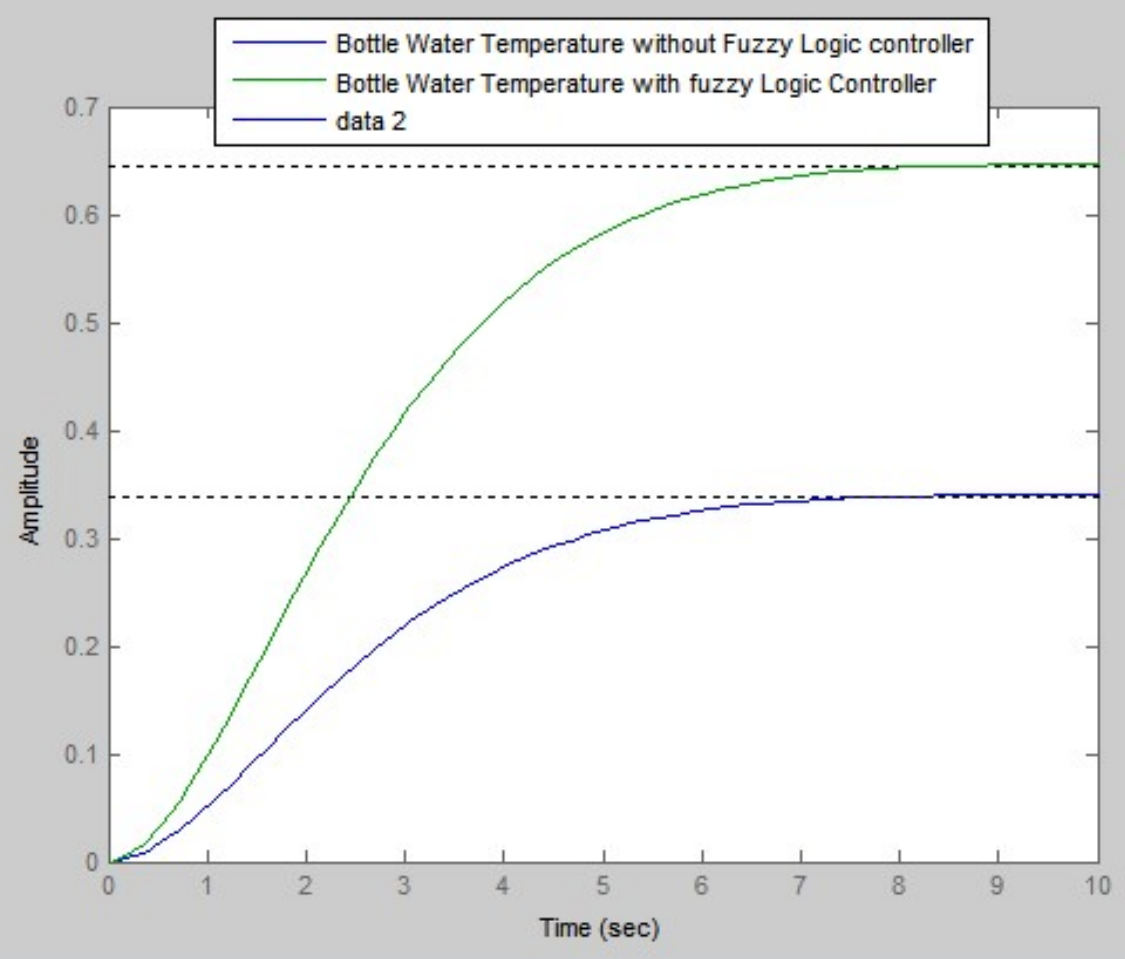

Fig2: steps response for Bottle water Temperature with and without fuzzy Logic Controller

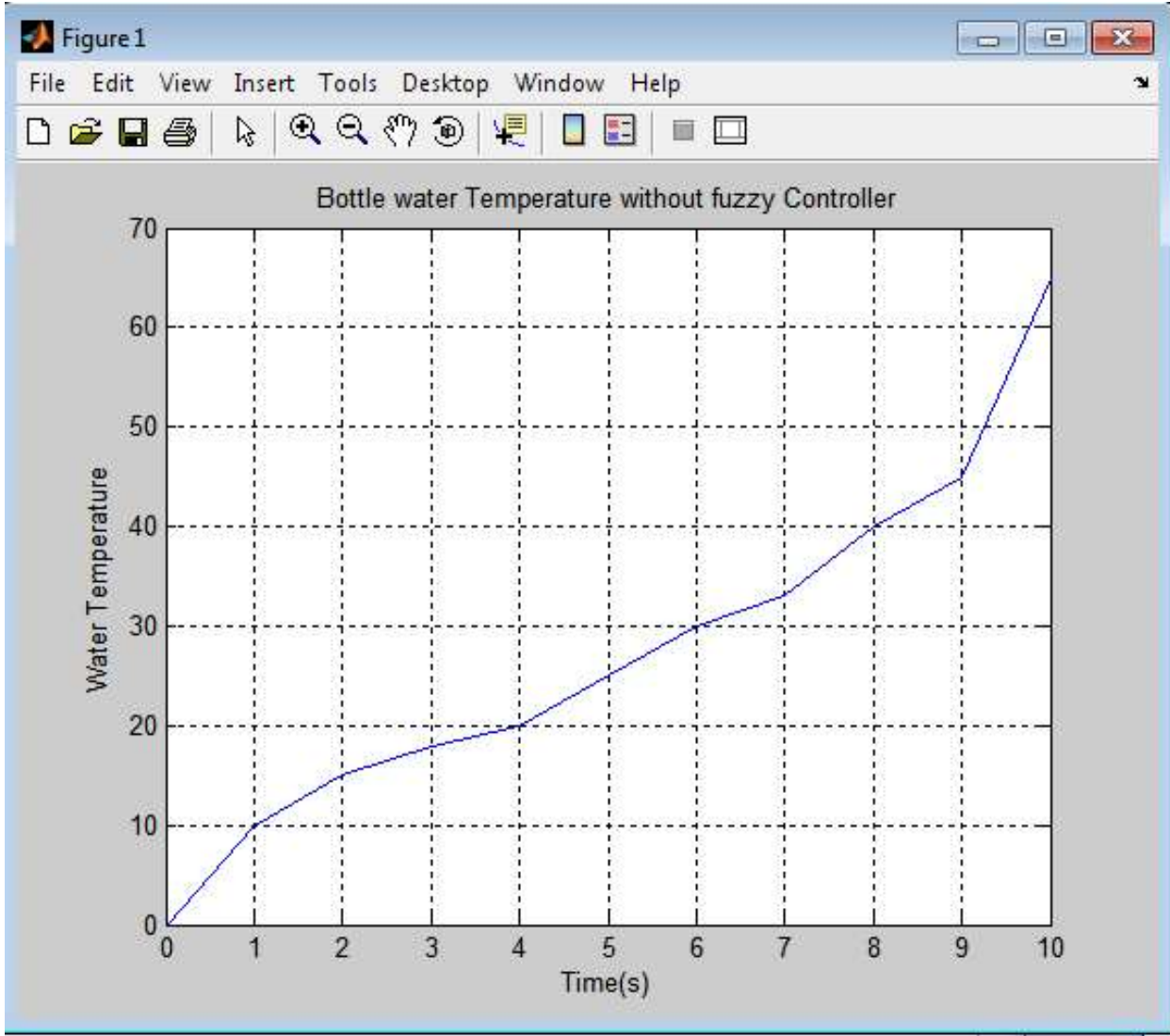

Fig3. The Bottle Water Temperature without Fuzzy logic controller. 


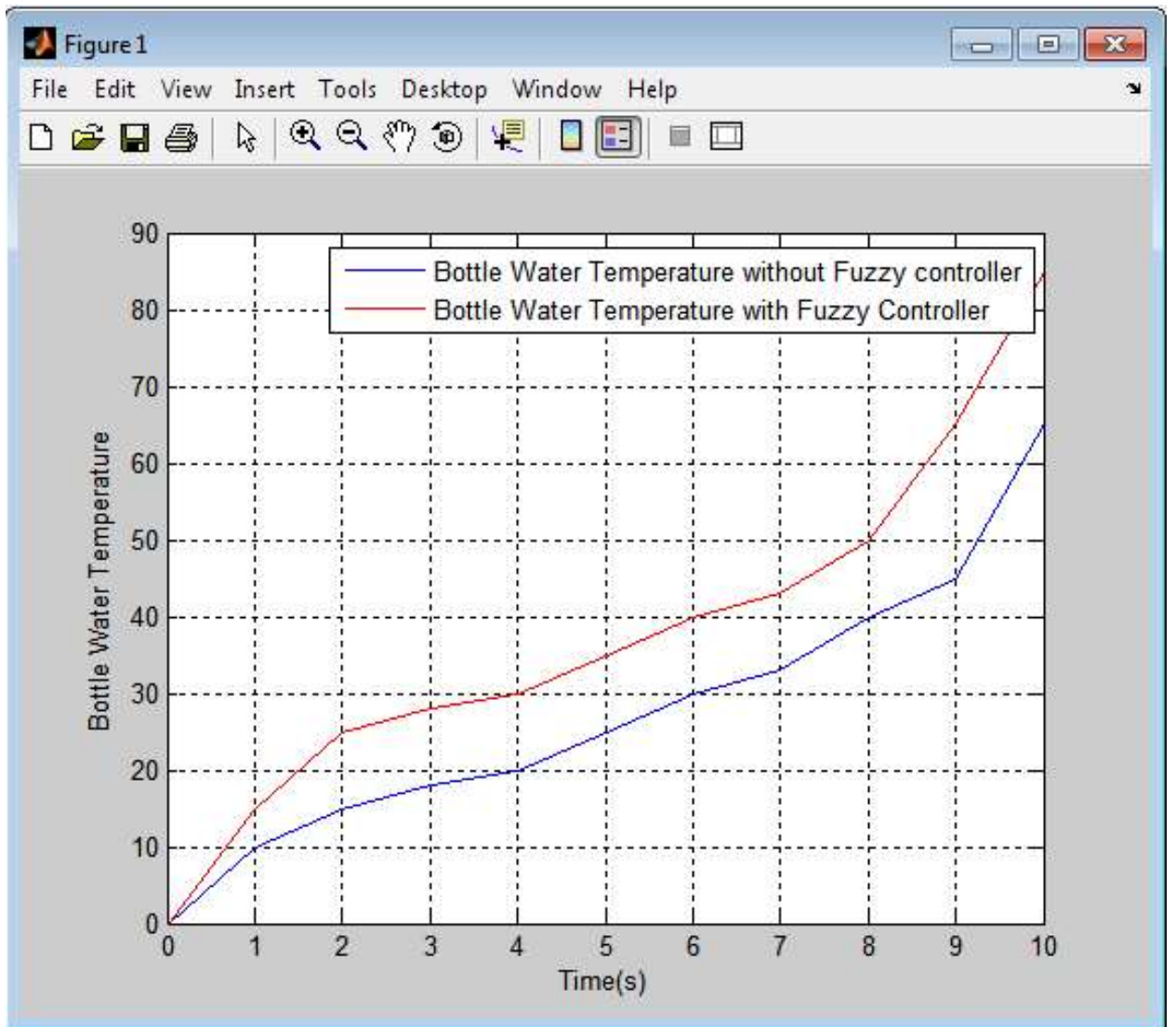

Fig4. Comparing the Bottle Water Temperature of industry with and without fuzzy controller

\section{Conclusion}

The instability of mathematical modeling which affect the performance of the Bottle water industry. it is crucial to control and Monitor water temperature within a specific period of time in order to avoid overshoot and absolute error, with better temperature tracking capability. Temperature control in Bottle water industries requires predetermined standard Temperature in order to determine temperature level of the water when the time varies. However, most industry does not have accurate and reliable monitoring mechanism capable of sensing when the water Temperature increases. This operational failure can be overcome by designing a model that will monitor and control the water temperature process thereby improving temperature control in water bottle industry using Fuzzy Logic Controller. MATLAB Software was used to carry out simulations to develop Temperature control in Bottle water industry with aims of improving operational mechanism of the industry. This model can then be trained with result gotten from the mathematical model in order to monitor and control the Water Temperature. The result showed that Bottle water Temperature with and without Fuzzy Logic Controller were $85^{\circ} \mathrm{C}$ and $65^{\circ} \mathrm{C}$ respectively. The Temperature increased by $20^{\circ \mathrm{C}}$. With these results, it shows that using fuzzy Logic Controller gives a better result than when fuzzy logic is not used.

\section{Reference}

[1] Asli Celikyilmaz and I. Burhan Trksen. Modeling Uncertainty with Fuzzy Logic: With Recent Theory and Applications. Springer Publishing Company, Incorpo- rated, 1st edition, 2009. ISBN 3540899235, 9783540899235

[2] Avneesh Mittal, Avinashi Kapoor, T.K. Saxena, "Genetic Algorithm Based Tuning of Fixed Bias PID Controller for a Nonlinear Constant Temperature Water Bath under Load Disturbances," J.Auomation \& System Engineering 6-3 (2012): 96-109.

[3] Bakhtiar I.Saeed, "Zero Overshoot and fast Transient Response using a Fuzzy Logic Controler," Procd. Of the Inter. Conf. On Autom. And Computing, pp. 116-120, 2011.

[4]Cheng- Hung Chen, "A Functional- Link-Based NeuroFuzzy Network for nonlinear control," IEEE Transactions on Fuzzy Systems, Vol. 16, pp. 1362-1377, 2008.

[5]Jafar Tavoosi, “A Novel Intelligent Control System Design For Water Bath Temperature Control,” Australian Journal of Basic And Applied Sciences, 5(12), pp. 1879-1885, 2011.

[6] J. S. R. Jang, C. T. Sun \& E. Mizutani, "Neuro-Fuzzy and Soft Computing," vol. I. New York: Prentice-Hall, 
pp. 460-463, 1997

[7] Marzuki Khalid, “A Neural Network Controller for a Temperature Control System,” IEEE Control Systems, pp.58-64, 1992.

(8) Nisha Jha, Udaibir Singh, I.K. Saxena \& Avianashi Kapoor, Online adaptive control for non Linear Processes Under Influence of External Disturbance, (IJAE), Volume (2) Issue (2): 2011, PP.36-46

[9]Om Prakash Verma and Himanshu Gupta, "Fuzzy Logic Based Water Bath Temperature Control System," International Journal of Advance Research in Computer Science and Software Engineering, Vol. 2, pp.333336, 2012.

[10]P. Melba Mary, "Design of Self-Tuning Fuzzy Logic Controller for the Control of an Unknown Industrial Process," IET Control Theory and Application, Vol.3, pp. 428-436, 2009.

[11]Rosso-Cerón A. M., Kafarov, V. and Latorre-Bayona, G. (2017): “A Fuzzy Logic decision support system for assessing sustainable alternative for power generation in non- interconnected areas of Colombia- case of study," Chemical Engineering Transactions, 57, 421-426.

[12]Radu-Emil Precup and Hans Hellendoorn. A survey on industrial applica- tions of fuzzy control. Computers in Industry, 62(3):213 - 226, 2011. ISSN 0166-3615. doi: http://dx.doi.org/10.1016/j.compind.2010.10.001.

[13]Rubiyah Yusof, Sigeru Omatu, Marzuki Khalid, "Application of Self- Tuning PI(PID) Contyroller to Temperature Control Syste,” Procd. Of the Inter. Conf. On third IEEE Conf., pp. 1181-1186, Vol. 2, 1994.

[14]Sung-Lin, H. (2012): “A fuzzy utility-based multi-criteria model for evaluating households' energy conservation performance: a Taiwanese case study," Energies, (5): 2818-2834.

[15]Thorin, E., Nordlander, E., Lindmark, J, Dahlquist, E, Yan, J., Fdhila, R. B. (2012): "Modeling of the biogas production process- a review."International Conference on Applied Energy ICAE: 1-9.

[16]Turkdogan-Aydıno, F. I. and Yetilmezsoy, K. (2010): "A fuzzy-logic-based model to predict biogas and methane production rates in a pilot-scale mesophilic UASB reactor treating molasses wastewater," Journal of Hazardous Materials, (182) 460-471.

[17]Z. Zhi, H. Lisheng, "Performance assessment for the water level control system in steam generator of the nuclear power plant", "IEEE/CCC”. Pp.5842-5847, July 2011.

[18]Zenned, S., Chaouali, H. and Mami, A. (2017): Fuzzy logic energy management strategy of a hybrid renewable energy system feeding a typical Tunisian house," (IJACSA) International Journal of Advanced Computer Science and Applications, 8(12): $206-212$. 